\title{
Sürekli Ayaktan Periton Diyalizi Hastalarında Gelișen Kültür Pozitif Peritonitlerin Epidemiyolojik ve Mikrobiyolojik Özelliklerinin Analizi
}

\author{
Sevil Alkan Çeviker*, Özgür Günal, Süleyman Sırrı Kılıç, Mehmet Derya Demirağ
}

DOI: 10.17944/mkutfd.541192

Sevil Alkan Çeviker: Uzm. Dr., Sağlık Bilimleri Üniversitesi Kütahya Evliya Çelebi Eğitim Araștırma Hastanesi, Enfeksiyon Hastalıkları ve Klinik Mikrobiyoloji Kliniği, Kütahya Eposta: s-ewil@hotmail.com

ORCID iD: https://orcid.org/0000-0003-1944-2477

Özgür Günal: Doç. Dr., Sağlık Bilimleri Üniversitesi Samsun Eğitim Araștırma Hastanesi, Enfeksiyon Hastalıkları ve Klinik Mikrobiyoloji Kliniği, Samsun Eposta: 0zgurgop@yahoo.com

ORCID iD: https://orcid.org/0000-0002-7744-4123

Süleyman Sırıı Kılıç: Prof. Dr., Sağlık Bilimleri Üniversitesi Samsun Eğitim Araștırma Hastanesi, Enfeksiyon Hastalıkları ve Klinik Mikrobiyoloji Kliniği, Samsun

Eposta: sskilic@yahoo.com

ORCID iD: https://orcid.org/0000-0002-0238-8008

Mehmet Derya Demirağ: Doç. Dr., Sağlık Bilimleri Üniversitesi Samsun Eğitim Araștırma Hastanesi, Romatoloji ve İç Hastalıkları Kliniği, Samsun Eposta: mehmetderyademirağ@yahoo.com ORCID iD: https://orcid.org/0000-0001-5667-1805

\section{Bildirimler/Acknowledgement}

Yazarlar bu makale ile ilgili herhangi bir çıkar çatıșması bildirmemișlerdir.

The authors declare that they have no conflict of interests regarding content of this article. Yazarlar bu makale ile ilgili herhangi bir finansal destek bildirmemișlerdir.

The Authors report no financial support regarding content of this article.

EKMUD Uluslarası Kongresi, 3 - 7 Nisan 2019 Antalya'da poster bildiri olarak sunulmuștur.

Received: 17.03.2019

Accepted: 22.05.2019

e-ISSN: 2149-3103

Web: http://dergipark.gov.tr/mkutfd
Öz

Sürekli Ayaktan Periton Diyalizi Hastalarinda Gelișen Kültür Pozitif Peritonitlerin Epidemiyolojik ve Mikrobiyolojik Özelliklerinin Analizi

Amaç: Sürekli Ayaktan Periton Diyalizi (SAPD) alan hastalarda gelișen peritonitler, bu hastalardaki artmış hastane ve antibiyotik maliyetlerinin, mortalite ve morbidite artıșının en önemli nedenlerindendir. Bu çalıșmada, SAPD hastalarında gelișen peritonitlerdeki etken mikroorganizmaların ve direnç profillerinin, bu hastalardaki demografik verilerin belirlenmesi amaçlanmıștır.

Gereç ve Yöntem: 0cak 2014- Ağustos 2018 tarihleri arasında, SAPD tedavisi alan ve peritonit tanısıyla Sağlık Bilimleri Üniversitesi Samsun Eğitim Araștırma Hastanesi icç Hastalıkları Kliniı̆íne yatırılarak izlenen hastalar retrospektif olarak incelendi. Vaka grubunu olușturan hastaların demografik ve laboratuvar verileri otomasyon sistemi ve tıbbi kayıtları incelenerek elde edildi.

Bulgular: Çalıșmamıza dahil edilen toplam 15 hastanın 7 (\%46.7) 'si erkek, 8 (\%53.3)'i kadın olup, yaș ortalaması 61.3 (47-78) yıl idi. 15 hastada gelișen toplam 44 peritonit atağı retrospektif olarak incelendi. Peritonit insidansı $1.51 \pm 1.46$ atak/ hasta yılı olarak saptandı. Çalıșmamızda, 9 (\%60) hastada multiple peritonit atağı, bir hastada 10 kez, bir hastada 7 kez, bir hastada 5 kez, dört hastada üçer kez ve iki hastada ikișer kez peritonit atağı geliștiği saptandı. Çalıșma grubundaki hastaların ikisinde relaps ( \%13.3), ikisinde rekürren ( \%13.3) ve $5(\% 33.3)^{\prime}$ inde tekrar eden peritonit görüldü. Multiple peritonit atağı gelișen hastaların ilk epizoda etkili antibiyotik tedavisini uygun sürede aldığı saptandı. Peritonit vakalarında en sık sorumlu mikroorganizmalar koagulaz negatif stafilokoklar (\%40.4) ve Escherichia coli (\%14.9) olarak saptandı. Üç (\%6.8) hastadan alınan kültürlerde polimikrobiyal üreme saptandı. 32 (\%68.1) kültürde gram pozitif, 15 (\%31.9) kültürde gram negatif bakteri üremesi oldu. Mantar üremesi ise saptanmadı.

Sonuç: Periton diyalizi alan hastalardaki peritonitlerin yönetimi için, her merkez kendine ait peritonit atak hızları ve etken mikroorganizmalar ile antibiyotik duyarlııkları takip edilmeli ve ampirik tedaviler buna göre düzenlenmelidir.

Anahtar kelimeler: Kronik böbrek yetmezliği, Sürekli Ayaktan Periton Diyalizi, Peritonit

\section{Abstract \\ Analysis of Epidemiological and Microbiological Characteristics of Culture-Positive Peritonitis in Continuous Ambulatory Peritoneal Dialysis Patients}

objective: Peritonitis in patients receiving continuous ambulatory peritoneal dialysis (CAPD) is one of the most important causes of increased hospital and antibiotic costs and mortality and morbidity in these patients. In this study, it was aimed to determine the microorganisms and resistance profiles of peritonitis in CAPD patients and to determine demographic data.

Materials and Methods: Between January 2014 and August 2018, patients who were treated with CAPD and hospitalized in the Internal Medicine Clinic with the diagnosis of peritonitis were retrospectively evaluated. Demographic and laboratory data of the patients in the case group were obtained by examining the automation system and medical records.

Results: of the 15 patients included in our study, 7 (46.7\%) were male and 8 (53.3\%) were female, with an average age of 61.3 (47-78) years. A total of 44 peritonitis episodes in 15 patients were evaluated retrospectively. The incidence of peritonitis was $1.51 \pm 1.46$ episodes / patient years. In our study, it was found that $9(60 \%)$ patients developed multiple peritonitis episodes, 10 patients in one patient, 7 times in one patient, 5 times in one patient, three times in four patients and two episodes in two patients. Two of the patients in the study group had relapse (13.3\%), two (13.3\%) had recurrent peritonitis and 5 (33.3\%) had recurrent peritonitis. It was determined that patients with multiple peritonitis episodes received effective antibiotic treatment in the first episode in the appropriate period. Coagulase negative staphylococci (40.4\%) and Escherichia coli (14.9\%) were the most common responsible microorganisms in peritonitis cases. Polymicrobial growth was detected in cultures taken from three (6.8\%) patients. Gram positive bacteria growth was positive in $32(68.1 \%)$ cultures and in $15(31.9 \%)$ cultures. Fungus growth was not detected.

Conclusion: For the management of peritonitis in patients receiving peritoneal dialysis, each center should have peritonitis attack rates and antibiotic susceptibility with causative microorganisms and empirical treatments should be adjusted accordingly.

Keywords: Chronic renal failure, continuous ambulatory peritoneal dialysis, peritonitis. 


\section{GİRIŞ̧}

Sürekli ayaktan periton diyalizi (SAPD) alan hastalarda gelişen peritonit, periton diyalizi (PD)'nin başlıca komplikasyonlarından biridir ve hastaların periton diyalizinden hemodiyalize geçişinin, hastaneye yatışın ve mortalitenin başlıca nedeni olmaya devam etmektedir $(1,2)$. PD hastalarının yaklaşık \%15-35'i peritonit tanısıyla hastaneye yatırılmaktadır. SAPD uygulamaya başlanmasından sonraki ilk 6 ayda en az bir kez peritonit gelişme oranı \%45, ilk yılda \%60-70 ve nüks peritonit geçirme olasılığının \%20-30 olduğu bildirilmiştir (3). Peritonit vakalarının büyük çoğunluğuna bakteriler (\%45-60 gram pozitif, \%15-35 gram negatifler) neden olmakla beraber, çoğunlukla Candida türleri olmak üzere, yaklaşık \%3 ila 5 oranında mantarlar da etken olarak saptanabilir. Ancak vakaların \%20- 40 'sinde etken tespit edilemez (4).

Sürekli ayaktan periton diyalizi alan hastalarda gelişen peritonitlerde erken ampirik tedaviler, mortalite ve morbiditenin azaltılmasına neden olmaktadır. Bu enfeksiyonlarda saptanan dirençli mikroorganizmalar tedavi yanıtsızlığına ve komplikasyonlara neden olabilir. Bu nedenlerden dolayı bu çalışmamızda, hastanemizde SAPD hastalarında gelişen peritonitlerde etken mikroorganizmaların tayini ve antibiyotik duyarlılıklarının değerlendirilmesi amaçlanmıştır.

\section{GEREÇ VE YÖNTEM}

Ocak 2014 - Ağustos 2018 tarihleri arasında, SAPD tedavisi alan ve peritonit tanısıyla Sağlık Bilimleri Üniversitesi Samsun Eğitim Araştırma Hastanesi İç Hastalıkları Kliniği'ne yatırılarak izlenen hastalar retrospektif olarak incelendi. Vaka grubunu oluşturan hastaların demografik ve laboratuvar verileri otomasyon sistemi ve tıbbi kayıtları incelenerek elde edildi. Demografik olarak yaş, cinsiyet, rutin biyokimyasal tetkikleri ve hemogram, C- Reaktif Protein (CRP) değerleri ile mikrobiyolojik olarak periton kültür sonuçları ve kültür antibiyogramları ile periton sıvılarının hücre sayımları ve gram boyamalarının incelendi. Peritonit tanısı; peritonit semptomları (karın ağrısı, ateş yüksekliği, üșüme titreme, bulantı ve kusma, vb) olan hastalardan alınan periton diyalizi sıvısı örneğinde $\mathrm{mm}^{3}$ 'te 100 'den fazla lökosit ve bu lökositlerin nötrofil hakimiyetinde (\%50'sinden fazlasının nötrofil) olması ve/veya periton sıvısı kültür örneğinden mikroorganizma izole edilmesi ve/veya pozitif gram boyamada mikroorganizma tespit edilmesi ile konuldu (1). Kültür negatif olgular çalışmaya dahil edilmedi.

Reküren peritonit, iki haftalık etkin tedavi alan hastalarda, tedavi sonrası dört hafta içerisinde ancak farklı mikroorganizmanın izole edildiği, relaps peritonit tedavi sonrası dört hafta içerisinde ancak aynı mikroorganizmanın izole edildiği, tekrar eden peritonit (repeat) ise 4 haftadan sonra aynı etken mikroorganizmanın izole edildiği peritonit olarak tanımlandı (5).

Kültürler ve antibiyogramlar hastanemiz mikrobiyoloji laboratuarındaVITEK® 2 (bioMérieux, Fransa) cihazı ve EUCAST tanı kriterlerine göre yapıldı (6).

\section{Etik Kurul Onayı}

Çalışmanın yapılabilmesi için Sağlık Bilimleri Üniversitesi Samsun Eğitim Araştırma Hastanesi yerel etik kurulundan 16.10.2018 tarihli TUEK 158-2018 GOKAEK/9-64_numarası ile etik kurul onayı alındı.

\section{BULGULAR}

Çalışmamıza dahil edilen toplam 15 hastanın 7 (\%46.7) «si erkek, 8 (\%53.3)'i kadın olup, yaş ortalaması 61.3 (47-78) yll idi. 15 hastada gelişen toplam 44 peritonit atağ pektif olarak incelendi. Peritonit insidansı 1.51 \pm 1.46 atak/ hasta yılı olarak saptandı. Çalışmamızda, 9 (\%60) hastada multiple peritonit atağı, bir hastada $10 \mathrm{kez}$, bir hastada 7 kez, bir hastada $5 \mathrm{kez}$, dört hastada üçer kez ve iki hastada ikişer kez peritonit atağı geliştiği saptandı. Çalışma grubundaki hastaların ikisinde relaps (\%13.3), ikisinde rekürren ( \%13.3) ve 5 (\%33.3)'inde tekrar eden peritonit görüldü. Multiple peritonit atağı gelişen hastaların ilk epizoda etkili antibiyotik tedavisini uygun sürede aldığı saptandı. Vaka grubunu oluşturan hastaların hiçbirisinin antibiyotik profilaksisi alma öyküsü yoktu. 2 hastada kateterle ilişkili peritonit atağı mevcuttu ve bu iki hastanın periton kateteri çekildi. Peritonit ataklarının yıllara göre dağılıma değerlendirildiğinde; 2014 yılında 10, 2015 yılında 7, 2016 yılında 1, 2017 yılında 19, 2018 yılında ise 7 peritonit atağı tespit edildi. Aylara göre dağılıma bakıldığında en sık Eylül (\%18.1), Ekim (\%13.6) ve Aralık (\%13.6) aylarında, mevsimlere göre ise en sık kış (\%34.1) ve sonbahar (\%31.8) mevsiminde peritonit ataklarının olduğu saptandı. Peritonit vakalarında en sık sorumlu mikroorganizmalar koagulaz negatif stafilokoklar (\%40.4) idi. Üç (\%6.8) hastadan alınan kültürlerde polimikrobiyal üreme saptandl. 32 (\%68.1) kültürde gram pozitif, 15(\%31.9) kültürde gram negatif bakteri üremesi oldu. En sık üreyen mikroorganizmalar, Koagulaz Negatif Stafilokoklar(KNS) (\%40.4) ve Escherichia coli (\%14.9) olarak saptandi (Tablo 1).

Peritonit vakalarının kültürlerinden üretilen $K N S S^{\prime} l a r ı n$ çeşitli antibiyotiklere direnç oranlarına bakıldığında en fazla direnç oksasiline (\%63.1), siprofloksasine (\%36.8) ve penisiline (\%47.3) karşı saptandı (Tablo 2). Streptokoklarda ise siprofloksasin, klindamisin ve tetrasiklin dirençleri \%16.6 olarak saptandı ( Tablo 3). 
Tablo 1. Sürekli Ayaktan Periton Diyalizi Hastalarında Gelișen Peritonitlerde Mikrobiyolojik Kültür Sonuçlarının Değerlendirilmesi.

\begin{tabular}{|c|c|c|}
\hline İzole Edilen Etkenler, (n:47) & & $\%$ \\
\hline Koagulaz Negatif Stafilokok & 19 & 40.4 \\
\hline - Staphylococcus epidermidis & 14 & 29.8 \\
\hline -Staphylococcus haemolyticus & 2 & 4.2 \\
\hline - Staphylococcus capitis & 2 & 4.2 \\
\hline -Staphylococcus saprophyticus & 1 & 2.1 \\
\hline Streptococcus spp. & 6 & 12.6 \\
\hline - Streptococcus acidominimus & 1 & 2.1 \\
\hline - Streptococcus pneumoniae & 1 & 2.1 \\
\hline - Streptococcus sanguinis & 1 & 2.1 \\
\hline -Streptococcus oralis & 1 & 2.1 \\
\hline - Streptococcus mitis & 1 & 2.1 \\
\hline -Granulicatella adiacens & 1 & 2.1 \\
\hline $\begin{array}{l}\text { (Nutrisyonel Varyant } \\
\text { Streptococcus spp.) }\end{array}$ & & \\
\hline Enterococcus faecalis & 1 & 2.1 \\
\hline MSSA & 3 & 6.3 \\
\hline Escherichia coli & 7 & 14.9 \\
\hline Acinetobacter baumanii & 3 & 6.3 \\
\hline Corynebacterium spp. & 1 & 2.1 \\
\hline Klebsiella pneumoniae & 1 & 2.1 \\
\hline Pseudomonas aeruginosa & 1 & 2.1 \\
\hline Serratia marcescens & 1 & 2.1 \\
\hline Stenotrophomonas maltophilia & 1 & 2.1 \\
\hline Enterobacter cloacaee & 1 & 2.1 \\
\hline Chryseobacterium indologenes & 1 & 2.1 \\
\hline Pasteurella spp. & 1 & 2.1 \\
\hline Polimikrobiyal üreme & 3 & 6.3 \\
\hline
\end{tabular}

*MSSA: metisilin duyarll S. aureus, spp.: Subspecies.

Peritonit vakalarının kültürlerinden üretilen E.coli cinsi bakterilerin çeşitli antibiyotiklere direnç oranlarına bakıldığında; en fazla direnç ampisiline (\%85.7) amoksisilin/ klavulanik asit (\%85.7) sefuroksim (\%85.7) karşı saptandı (Tablo 4). Ayrıca; üretilen 7 E.coli'den 4'ünde Genişlemiş Spektrumlu Beta-laktamaz (GSBL) varlığı olduğu saptandı.
Tablo 2. Peritonit vakalarının kültürlerinden üretilen Koagulaz Negatif Stafilokok'ların çeşitli antibiyotiklere direnç oranlarının değerlendirilmesi.

$\begin{array}{lll}\text { Antibiyotik adı } & \mathbf{n : 1 9} & \text { \% } \\ \text { Penisilin } & 9 & 47.3 \\ \text { Klindamisin } & 7 & 36.8 \\ \text { Vankomisin } & 0 & 0 \\ \text { Rifampisin } & 6 & 31.6 \\ \text { Tetrasiklin } & 4 & 21.1 \\ \text { Gentamisin } & 3 & 15.7 \\ \text { Teikoplanin } & 0 & 0 \\ \text { Trimetoprim- } & 3 & 15.7 \\ \text { sulfametaksazol } & 7 & 36.8 \\ \text { Siprofloksasin } & 12 & 63.1 \\ \text { Oksasilin } & 2 & 10.5 \\ \text { Fusidik asit } & 0 & 0 \\ \text { Tigesiklin } & 0 & 0 \\ \text { Linezolid } & \end{array}$

Tablo 3. Peritonit vakalarının kültürlerinden üretilen Streptococcus cinsi bakterilerin çeşitli antibiyotiklere direnç oranlarının değerlendirilmesi.

$\begin{array}{lll}\text { Antibiyotik adı } & \mathbf{n : 6} & \mathbf{\%} \\ \text { Penisilin } & 0 & 0 \\ \text { Klindamisin } & 1 & 16.6 \\ \text { Vankomisin } & 0 & 0 \\ \text { Tetrasiklin } & 1 & 16.6 \\ \text { Teikoplanin } & 0 & 0 \\ \text { Seftriakson } & 0 & 0 \\ \text { Siprofloksasin } & 1 & 16.6 \\ \text { Linezolid } & 0 & 0\end{array}$

\section{TARTIŞMA}

Sürekli ayaktan periton diyalizi, hemodiyaliz tedavisine göre komplikasyon riski daha düşük olan ve hastalar için daha konforlu kabul edilen bir tedavi yöntemidir. Ancak SAPD alan hastalarda, sosyodemografik, iklimsel, PD türü ve peritoneal kateter çıkış yeri enfeksiyonu veya kateter tünel enfeksiyonu varlığı gibi birçok faktöre bağlı olarak peritonit gelișebilir $(1,2,7)$. Eşlik eden diabetes mellitus (DM), koroner arter hastalığı, kronik pulmoner hastalık varlığı, obezite, kadın cinsiyet, serum albumin düzeyinin düşük olması, aktif sigara kullanımı, stafilokokal nazal tașıyıcılık ve antibiyotik kullanım hikayesi gibi literatürde birçok risk faktörü bildirilmiştir $(8,9,10)$. Çalışmaya dahil edilen 15 hastanın 7 (\%46.7) 'si erkek, 8 (\%53.3)'i kadın olup cinsiyet faktörü, peritonit gelişimi için istatistiksel olarak anlamlı saptanmadı ( $p>0.05)$. Çalışmamızda diğer risk faktörleri vaka sayısının yetersiz olması ve dosya taramalarında yeterli bilgiye ulaşılamaması nedeniyle değerlendirilemedi. 


\begin{tabular}{lll}
\multicolumn{2}{l}{ Tablo 4. Peritonit vakalarının kültürlerinden üretilen E.coli cinsi bakterilerin } \\
çeşitli antibiyotiklere direnç oranlarının değerlendirilmesi. \\
Antibiyotik adı & $\mathbf{n : 7}$ & $\%$ \\
Siprofloksasin & 5 & 71.4 \\
Ampisilin & 6 & 85.7 \\
Amoksisilin/Klavulanik & 6 & 85.7 \\
asit & & \\
Ampisilin /Sulbaktam & 6 & 85.7 \\
Gentamisin & 5 & 71.4 \\
Piperasilin & 5 & 71.4 \\
Tazobaktam/Piperasilin & 4 & 57.1 \\
Ertapenem & 0 & 0 \\
Meropenem & 0 & 0 \\
İmipenem & 0 & 0 \\
Seftriakson & 5 & 71.4 \\
Seftazidim & 4 & 57.1 \\
Sefepime & 4 & 57.1 \\
Sefoksitin & 5 & 71.4 \\
Sefuroksim & 6 & 85.7 \\
Amikasin & 3 & 42.8 \\
Tigesiklin & 0 & 0
\end{tabular}

Sürekli ayaktan periton diyalizi hastalarında peritonit; periton boşluğuna mikroorganizmaların kateter lümeni vasıtasıyla girmesiyle veya kateter çıkış yeri / kateter tünel enfeksiyonuna sekonder gelişebilir. Kateter lümeninden periton boşluğuna geçiş durumunda etken genellikle cilt flora bakterileri olarak saptanır $(11,12)$. Abraham ve ark. (13) çalışmalarında periton kültürlerinden, gram negatif bakterileri \%47.8, gram pozitif bakterileri \%36.7, fungal etkenleri \%13.3 ve Mycobacterium tuberculosis 'i \%2.2 oranında izole etmișlerdir. Çalıșmamızda, 32 (\%68.1) kültürde gram pozitif, 15 (\%31.9) kültürde gram negatif bakteri üremesi oldu. Mantar üremesi ise saptanmadl.

Ülkemizden yapılan çeşitli çalışmalarda, SAPD hastalarında peritonit ataklarında S. epidermidis en sık etken mikroorganizma olduğu bildirilmiştir $(14,15)$. Bizim çalışmamızda da en sık etken KNS (\%40.4) olup, en sık izole edilen KNS alt türü çalışmalarla benzer olarak S. epidermidis (\%29.8) idi. KNS dışında ikinci sıklıkta E.coli (\%14.9) izole edildi.

Gupta ve ark. (2) Sharma ve ark. (16) çalışmalarında SAPD gelişen hastaların periton kültürlerinden en sık gram negatif bakteri olarak E. coli izolasyonu olduğunu bildirmişlerdir.

Çalışmamızda da gram negatif üreme 15 (\%31.9) kültürde saptandı ve en sık izole gram negatif mikroorganizmalar E. coli (\%14.9) idi. Literatürde polimikrobiyal peritonit oranı \%1-\%15.26 arasında bildirilmektedir $(4,17)$.
Çalışmamızda, üç (\%6.3) hastadan alınan kültürlerde polimikrobiyal üreme saptandı.

Çeşitli çalışmalarda relaps peritonit oranı \%8-10, tekrar eden peritonit atağ $(18,19)$. Periton diyalizi hastalarından alınan peritoneal kateterlerdeki biyofilm takabanın varlığının $S$. aureus veya S. epidermidis için aynı organizma ile relaps peritonit veya tekrarlayan peritonite katkıda bulunabileceği bildirilmiştir (20). Naz ve ark. (21) çalışmalarında peritonit görülen hastalarda relaps oranını \%16.7, tekrar eden peritonit oranı \%19 olarak bildirmişlerdir. Çalışmamızda, 9 (\%60) hastada multiple peritonit atağı, bir hastada $10 \mathrm{kez}$, bir hastada $7 \mathrm{kez}$, bir hastada $5 \mathrm{kez}$, dört hastada üçer kez ve iki hastada ikişer kez peritonit atağı geliştiği saptandı. Çalışma grubundaki hastaların ikisinde relaps ( \%13.3), ikisinde rekürren (\%13.3) ve 5 (\%33.3)'inde tekrar eden peritonit görüldü. Tüm tekrarlayan ataklarda en sık oranda tespit edilen mikroorganizma S. epidermidis (\%46.6) idi.

Tekin Koruk ve ark. (22) periton diyaliz hastalarında peritonitleri inceledikleri çalışmalarında, periton kültürlerinden izole ettikleri tüm stafilokok suşlarında metisilin direncini \%38.7 olarak bildirmişleridir. Ayrıca stafilokok suşlarında glikopeptid direncine rastlamamışlardır. Bizim çalışmamızda da KNS kökenlerinde, oksasilin direnci \%63.1 olarak saptandı ve glikopeptid direncine rastlanmadı.

Literatürde, SAPD ile ilişkili peritonitin vakaların \% 80 85'ine kadar etkili bir şekilde tedavi edilebildiğini birçok çalışma göstermiştir (23). Ancak bu hastaların ampirik antibiyotik tedavilerinin peritonit tanısı konulur konulmaz hemen başlanması, merkezlerin kendi antibiyotik duyarlılık sonuçlarına göre ampirik tedavilerinin belirlenmesi ve üreme olursa duyarlılık sonuçlarına göre tedavilerin modifiye edilmesi gerekmektedir. Ayrıca semptomu olan hastalara oral tedavi rehberler tarafından önerilmemektedir. Ampirik tedavide sefazolin gibi birinci kuşak sefalosporin ile birlikte antipsödomonal etkinlikte bir antibiyotik kombinasyonu önerilmektedir. Ancak metisilin direncinin yüksek olduğu merkezlerde antipsödomonal etkinlikte bir antibiyotik ile vankomisin kombinasyonu önerilmektedir $(5,23)$. Bizim çalışmamızda da hastaların tümüne, birinci kuşak sefalosporin ile birlikte antipsödomonal etkinlikte bir antibiyotik kombinasyonu intravenöz ve intraperitoneal verildiği ve kültür sonuçlarına göre antibiyotik tedavileri düzenlendiği saptandı. Tüm hastalarda 14-21 günlük tedaviler sonrasında, mikrobiyolojik ve biyokimyasal kür sağlandığı saptandı.

Literatürde, SAPD ile ilişkili peritonit ile ilişkili mortalite \%6-8 olarak bildirilmektedir $(23,24,25)$. Çalışmamızda peritonit gelişen hastaların hiçbirisinde mortalite gelişmedi. Bu durumun, hastaların hastaneye peritonit semptomları başlar başlamaz başvurmalarına ve uygun ampirik tedavilere bağlı olabileceğini düşünmekteyiz. 


\section{SONUÇ}

Sonuç olarak; periton diyalizi alan hastalardaki peritonitlerin yönetimi için, her merkez kendine ait peritonit atak hızlarını takip etmeli, vaka sayısı arttığında enfeksiyon kontrol önlemlerinin gözden geçirilmesi bașta olmak üzere müdahaleler uygulamalıdır. Ayrıca etken mikroorganizmaları ve antibiyotik duyarlılıklarını takip etmeli ve ampirik tedaviler buna göre düzenlenmelidir. Yine SAPD ilişkili peritonitlere neden olan etkenler, tedavi stratejileri ve bu enfeksiyonların engellenmesi amaçlı çok merkezli prospektif çalışmaların yapılması gerektiği kanaatindeyiz.

Çalışmanın kısıtlılıkları: Çalışmamızda vaka sayısının yetersiz olması ve dosya taramalarında hastalara ait risk faktörleri açısından yeterli bilgiye ulaşılamaması nedeniyle bazı parametrelerde yeterli sonuçlara ulaşılamamıştır.

\section{KAYNAKLAR}

1. Liakopoulos V, Nikitidou O, Kalathas T, Roumeliotis S, Salmas M, Eleftheriadis T. Peritoneal dialysis-related infections recommendations: International Society of Peritoneal Dialysis (ISPD) 2016 update. What is new?. Int Urol Nephrol 2017;49(12):21772184.

2. Gupta S, Muralidharan S, Gokulnath, Srinivasa H. Epidemiology of culture isolates from peritoneal dialysis peritonitis patients in Southern India using an automated blood culture system to culture peritoneal dialysate. Nephrology (Carlton.) 2011;16:63-7.

3. Levison ME, Bush LM. Peritonitis and intraperitoneal abscesses. In: Mandell GL, Bennett JE, Dolin R, (Editors). Mandell, Douglas, and Bennett's Principles and Practice of Infectious Diseases. 7th ed. Philadelphia: Churchill Livingstone, 2010.p.1027-1030.

4. JM Burkart. Microbiology and therapy of peritonitis in peritoneal dialysis - UpToDate.

5. Li PK-T, Szeto CC, Piraino B, de Arteaga J, Fan S, Figueiredo AE, et al. ISPD Peritonitis recommendations: 2016 update on prevention and treatment. Perit Dial Int 2016; 36:481-508.

6. The European Committee on Antimicrobial Susceptibility Testing. Breakpoint tables for interpretation of MICs and zone diameters. Version 4.0, 2014. Erişim:http://www.eucast.org/fileadmin/src/ media/PDFs/EUCAST_files/Breakpoint_tables/Breakpoint_ table_v_4.0.pdf

7. van Diepen AT, Tomlinson GA, Jassal SV. The association between exit site infection and subsequent peritonitis among peritoneal dialysis patients. Clin J Am Soc Nephrol 2012; 7:1266-71.

8. Kotsanas D, Polkinghorne KR, Korman TM, Atkins RC, Brown F. Risk factors for peritoneal dialysis-related peritonitis: can we reduce the incidence and improve patient selection? Nephrology 2007; 12: 23945.

9. Chow KM, Szeto CC, Leung CB, Kwan BC, Law MC, Li PK. A risk analysis of continuous ambulatory peritoneal dialysis-related peritonitis. Perit Dial Int 2005; 25:374-9.
10. McDonald SP, Collins JF, Rumpsfeld M, Johnson DW. Obesity is a risk factor for peritonitis in the Australian and New Zealand peritoneal dialysis patient populations. Perit Dial Int 2004; 24:340-6.

11. Steer JA, Hill GB, Srinivasan S, Southern J, Wilson AP: Slime production, adherence and hydrophobicity in coagulase-negative staphylococci causing peritonitis in peritoneal dialysis. J Hosp Infect 1997;37:305-316

12. Read RR, Eberwein P, Dasgupta MK, Grant SK, Lam K, Nickel JC, et al: Peritonitis in peritoneal dialysis: Bacterial colonization by biofilm spread along the catheter surface. Kidney Int 1989;35:614-621

13. Abraham G, Gupta A, Prasad KN, Rohit A, Bhalla AK,et al.Microbiology, clinical spectrum and outcome of peritonitis in patients undergoing peritoneal dialysis in India: Results from a multicentric, observational study.Indian J Med Microbiol 2017;35(4):491-498.

14. Karadenizli A, Yeğenağa-Bakioğlu I, Kolaylı F, Koçanali Y, Bingöl R. Kronik ambulatuar periton diyalizi hastalarının bakteriyolojik yönden irdelenmesi. Klimik Derg 2002;15:59-51.

15. Çolak B, Hızel K, Güz G ve ark. Periton diyaliz hastalarında peritonit sıklığı ve risk faktörleri. Flora Dergisi. 2004;9:266-70.

16. Sharma RK, Kumar J, Gupta A, Gulati S. Peritoneal infection in acute intermittent peritoneal dialysis. Ren Fail 2003;25:975-80.

17. Gloor HJ, Pandolfi S, Rüttimann S. 20 years of peritoneal dialysis in a mid-sized Swiss hospital. Swiss Med Wkly 2003; 133: 619-24.

18. Leppanen H, Metsarinne KP, Nikoskelainen J, Tertti R. Three-year analysis of microbial aetiology and antimicrobial susceptibilities of PD peritonitis. Scan J Infect Dis 2006; 38: 645-49.

19. Kavanagh D, Prescott GJ, Mactier RA. Peritoneal dialysis-associated peritonitis in Scotland (1999-2002). Nephrol Dial Transplant 2004; 19: 2584-91.

20. Dasgupta MK, Ulan RA, Bettcher KB, et al. Effects of exit site infection and peritonitis on the distribution of biofilm-encased adherent bactereial microcolonies (BABM) on Tenchkhoff (T) catheters in patients undergoing continuous ambulatory. In: Advances in Continuous Ambulatory Peritoneal Dialysis, Khanna R, Nolph KD, Prowand BF, et al (Eds), University of Toronto Press. Toronto. 1986.102.

21. Naz H , Şahin G, Serbest S , Yalçın AU. Periton Diyalizi İle İlișkili Peritonit: 179 Atağın Değerlendirilmesi. Mikrobiyol Bül 2008; 42 265-272.

22. Koruk ST, Yetkin MA, Koruk İ, Erdinç FŞ, Şahan S, Tülek N. Sürekli Ayaktan Periton Diyalizi Uygulanan Hastalarda Gelișen Peritonit Ataklarının Değerlendirilmesi. Flora Derg. 2006;11(1):24-31.

23. Ramanathan K, Padmanabhan G, Vijayaraghavan B. Evaluation of continuous ambulatory peritoneal dialysis fluid C-reactive protein in patients with peritonitis. Saudi J Kidney Dis Transpl 2016; 27(3): $467-72$.

24. Troidle L, Finkelstein F. Treatment and out- come of CPD-associated peritonitis. Ann Clin Microbiol Antimicrob 2006;5:6.

25. van Esch S, Krediet RT, Struijk DG. 32 years' experience of peritoneal dialysis-related peri- tonitis in a University Hospital. Perit Dial Int 2014;34:162-70. 